\title{
Development of Artificial Intelligence by Ensembles of Virtual Agents with Mobile Interaction
}

\author{
Evgeniy Bryndin \\ Research Department, Research Center "Natural Informatics", Novosibirsk, Russia
}

\section{Email address:}

bryndin15@yandex.ru

\section{To cite this article:}

Evgeniy Bryndin. Development of Artificial Intelligence by Ensembles of Virtual Agents with Mobile Interaction. Automation, Control and Intelligent Systems. Vol. 8, No. 1, 2020, pp. 1-8. doi: 10.11648/j.acis.20200801.11

Received: January 4, 2020; Accepted: January 10, 2020; Published: April 13, 2020

\begin{abstract}
Process automation, cloud technology, machine learning, big data analytics, and the Internet of Things have changed the fundamental pillars of the high-tech industry, according to Deloitte's report of Future of Working in the World of Technology. The Harvard Business Review Analytic Services study to marks the race for technology across all industries. The digital transformation of the high-tech industry and social sphere currently requires rapid reactions and flexible mobility. Smart collaboration agents are beginning to demonstrate the ability to work together effectively. Smart agent ensembles use information from technology platforms such as the European Technology Platform Future Manufacturing Technologies and analytics platforms such as Visiology, which quickly and efficiently addresses the challenges of collecting, analyzing and visualizing large amounts of data. Fast, efficient data collection and analysis of large amounts of data, flexible operational mobility of data updates, and synergistic open collaboration of smart agents with information platforms and analytical systems will help accelerate the digital transformation of the high-tech industry and social sphere by teaching new skills. Learning new skills can be done in a virtual space and then developed in a specific environment. The accumulation of professional experience in virtual space contributes to the development of artificial intelligence.
\end{abstract}

Keywords: Virtual Ensemble of Agents, Technological Platforms, Analytical Systems, Development of Artificial Intelligence

\section{Introduction}

In classical artificial intelligence theory, the solution to any problem is to create some one intelligent system, called an agent, which, having at its disposal all the necessary knowledge, abilities and computational resources, is able to solve some global problem. Multi-agent systems are the direction of artificial intelligence that uses ensembles consisting of multiple interacting agents to solve a complex problem or problem. In multi-agent systems, the entire spectrum of tasks under certain rules is distributed among all agents, each of whom is considered a member of the ensemble. Job allocation means assigning each agent a role whose complexity is determined by the agent's capabilities.

To organize the task distribution process, a multi-agent system creates either a distributed problem resolution ensemble or decentralized artificial intelligence. In the first version, the process of decomposition of the global problem and the inverse process of composition of found solutions takes place under centralized control. At the same time, the multi-agent system is designed strictly from top to bottom, based on the roles defined for the agents and the results of dividing the global task into subtasks. In the case of decentralized artificial intelligence, job distribution occurs during agent interaction. This results in resonance, synergistic effects in multi-agent systems.

Multi-agent ensembles are an actively developing direction of artificial intelligence that is still in its formative stages. Work in multi-agent ensembles requires attracting knowledge and technology from a number of areas that were previously out of sight of artificial intelligence professionals. Integration of multi-agency ensembles - technological platforms analytical systems, brings a number of fundamentally new properties and opportunities to information technologies and in fact represents a qualitatively new, higher level of its development, the level that allows to predict its leading position in the coming decades [1-8]. Artificial intelligence professionals have a leading role here. 
Already today the agency-oriented approach finds wide application in such areas as distributed solution of complex tasks and efficient solution of distributed tasks, combined design of products, re-engineering of business and construction of virtual enterprises, simulation modeling of integrated production systems and electronic commerce, organization of work of robot collectives and distributed (combined) development of computer programs. In the near future, it will undoubtedly take a central place in the development of information and knowledge management tools, and of course, in the creation and implementation of the latest telecommunications systems, the development of global computer networks, especially the Internet.

The proposed direction is a new interdisciplinary science of synergistic artificial intelligence, in which systemic qualities of synergistic effects arise in the process of joint action and mutual adaptation of individual information or communication technologies, which is connected with strengthening of capabilities and compensation of disadvantages of individual components. Based on the system approach, we will consistently consider the components of the triad: technological platforms - virtual analytical systems - ensembles of mobile agents.

\section{Technological Platforms}

Technology platforms are partnership mechanism aimed at rapid development of research and development by creating a basis for interaction between participants and the most significant developments for development, forming answers to strategic technological challenges.

Technology platforms are platforms for implementing the relationships of applied research and technology transfer. They bring together stakeholders and provide dialogue, mobilize and direct existing research and development opportunities, identify new scientific and technological opportunities for modernization, and promote a more effective approach to innovation. They are focused on using best practices and expertise in the global space, focusing interdisciplinary research on linking promising industry technologies to the competencies of the future.

Principles of interaction with technological platforms: openness to join and information transparency; increase in awareness; identity of organizational structure; internationality.

Participants in technology platforms may include research institutes and the academic community; researchers; Industry and other regulatory structures.

Connections to technology platforms can be horizontal, vertically oriented, distributed, research multi-crossdisciplinary, sectoral and other.

Technologically advanced countries such as the United States, Germany, France, Great Britain, Japan, Israel, China, Australia, Singapore, Canada, Sweden, Belgium are predominantly with currently developing technology platforms. US innovation strategies are developed on the basis of technology platforms. The University of Manchester has brought together transnational corporations from different industries (Astra-Zeneca, IBM, BP, Syngenta). ETP's European technology platforms deal with technology issues that could potentially contribute to a number of key challenges essential for the development and adoption of modern technologies, the creation of technologies for the sustainable development of society, social goods and services based on advanced technologies, technological breakthroughs needed to remain at the forefront of high technology sectors and the restructuring of traditional industry. ISTOK-SOYUZ project ("Information Society Technologies to Open Knowledge for Eastern Europe and Central Asia") is supported by the European Commission. The aim of the project is to provide new opportunities for cooperation in the field of ICT (information and communication technologies) between the European Union (EU), Eastern Europe and the countries of Central Asia (EECA), as well as to facilitate the information programs of the European Union in the field of ICT, including partners from the above-mentioned countries, in particular Russia, Ukraine, Belarus, Armenia and Kazakhstan. ARTEMISIA European Technology Platform for Research and Development in Advanced Research and Embedded Systems Technologies. It was established in 2007 by Daimler, Nokia, Philips, STMicroelectronics and Thales.

Previously, geographical concentration was an important feature of the technology platform. With the development of the Internet, this need has disappeared, and the type and nature of connections have been transformed. This fact has led to the development of international strategic innovation alliances that promote the mobility of research and skills.

\section{Virtual Analytical System}

There is approach to building unified virtual analysis system based on model analysis matrix. The basic elements of the unified virtual analysis system are virtual analyzers, which are software-algorithm complexes that implement functions of in-depth assessment of the current state and its evolution. The main sources of information for virtual analysis are retrospective technological knowledge accumulated and stored in databases. Visiology ViQube, an analytical multidimensional database, has the ability to support multi-dimensional and relational (SQL-like) queries, store multi-dimensional metadata directly in the DBMS, customize data import from Excel and SQL sources via the web interface, real-time data addition and deletion, and run analytical queries by third-party systems. For example, to optimize the research process by collecting, processing data, and building a self-learning model based on Big Data using neural networks.

The main potential of virtual analytical systems development is aimed at creation of solutions based on information processing in the field of work with Big Data through distribution of audio and video equipment (Promethean, Epson, Pasco Scientific, Apple, AverMedia, Sony). Working with modern DBMS: Oracle, SQLServer, MySQL, PostgreSQL. Build a data model to meet specific 
customer needs. Storage of big data in HDFS, Hive, Pig, HBaseand their processing and computation with Spark. Non-standard visualization on JavaScript, d3. js, and highcharts. js. Project Management: PMI PMBoK.

\section{Synergy of Mobile Agents, Technology Platforms and Analytical Systems}

Ensembles of clever agents have mobility and a welldeveloped and replenished symbolic model of the outside world thanks to their BZ, reasoning and analysis of actions. Smart agent mobility is the ability to migrate across technology platforms in search of the necessary information with reference to analytical systems to analyze it.

Virtual ensembles contain many smart mobile intelligent agents distributed throughout the world that migrate through it in search of relevant data, knowledge, procedures on technology platforms and analytical systems and co-operate to achieve their goals. The intelligent behavior of the agent is provided by the ability to take decisions. The connective architecture of a smart robot allows the use of self-learning intelligent agents, the principles of which are formed in the process of solving practical problems.

The interaction of virtual smart agents establishes bilateral and multilateral relations between the ensemble, technology platforms and analytical systems. It is a prerequisite for building virtual communities. Interaction is accompanied by the mutual transformation of the agents themselves and the relationship between them. The main characteristics of any interaction are orientation, selectivity, intensity and dynamism:

1. Orientation - positive or negative; cooperation or competition; coordination or subordination, etc.;

2. Selectivity - interaction takes place between agents that in any way correspond to each other and the task. The agents may be bound in an ordinary relation and independent in another;

3. Intensity - interaction between agents is not related to presence or absence, but is characterized by determined force;

4. Dynamism - the presence, strength and direction of interactions can change over time.

Agent interaction analysis includes the following tasks:

1. Identification of the situation of interaction of agents;

2. Allocation of core roles and their distribution among agents;

3. Determination of the number and types of interacting agents;

4. Building a formal interaction model;

5. Defining a set of possible strategies for agents 'behavior;

6. Formation of multiple communicative actions.

Each agent has a limited set of knowledge needed to achieve his or her own and common goals. Commitments are one of the tools to streamline the chaotic relationships of agents. They allow you to anticipate the behavior of other agents, predict the future and plan your own actions. The following groups of obligations can be distinguished: (a) obligations to other agents; B) the agent's obligations to the group; C) the group 's obligations to the agent; D) obligation of the agent to himself. The formal presentation of goals, commitments, desires and intentions, as well as all relevant characteristics, forms the basis of the mental model of the internal agent, which ensures its motivated behavior.

Different forms of interaction between agents arise:

1. Simple cooperation, which involves integrating the experience of individual agents (task allocation, knowledge sharing, etc.) without special measures to coordinate their actions;

2. Coordinated collaboration where agents are forced to coordinate their actions (sometimes involving a special coordinating agent) in order to use resources and their own expertise effectively;

3. Productive collaboration where agents share resources or solve a common problem by sharing experiences without interfering with each other.

The most known models of coordination of behavior of agents are: game-theoretic models, models of collective behavior of automatic machines, models of planning of collective behavior, model on the basis of BDI architecture (Belief - Desire - Intention), models of coordination of behavior on the basis of the competition.

A smart robot solves many tasks in the process of teamwork of mobile agents:

1. Recognition of the need for cooperation;

2. Selection of suitable partners

3. Ability to consider partner interests

4. Organization of negotiations on joint actions;

5. Development of joint action plans;

6. Synchronization of joint actions;

7. Task decomposition and division of duties;

8. Identifying conflicting targets;

9. Competition for shared resources;

10. Formation of rules of conduct in the team;

11. Team behavior training, etc.

A feature of the collective behavior of mobile agents is that their interaction in the process of solving private tasks (or one general) creates a new quality of solving these problems. To do this, mobile agents can leave the client server and change to the remote server to perform their actions, so that they can return. The use of mobile agents ensures:

1. Reduced time and cost of data transmission;

2. Expansion of limited local resources

3. Coordination simplification;

4. Performing asynchronous calculations.

Special tools have been developed to support agent design processes and multi-agent systems. Consider the subject of Agent Builder as an example. The Agent Builder (Reticular Systems, Inc.) is designed for the development of multi-agent systems based on Java programs, which allows them to be executed on any computer where a Java Virtual Machine is installed.

The mobile agent lifecycle model includes the following steps:

1. Processing of new messages; 
2. Definition of rules of conduct;

3. Performance of actions;

4. Updating the mental model according to the specified rules;

5. Planning of actions.

The mental model includes a description of the intentions, desires, obligations and capabilities, and rules of conduct of agents. Based on this model, you select specific intelligent agent settings.

Agent Builder behavior rules are implemented in a special object-oriented RADL (Reticular Agent Definition Language) as a When-If-Then construct.

As a sufficiently powerful tool for presenting and processing knowledge, Agent Builder does not provide explicit logical output controls that could significantly enhance the capabilities of the language used.

Due to the rapid development of Internet technologies, it was necessary to use artificial intelligence tools to search for and process Internet resources. The use of Intel mobile agents for the collection, search and analysis of information in global networks provides the following capabilities:

1. Parallel solution of several tasks;

2. Creation of own databases of information resources, which are constantly updated and expanded;
3. Realization of the possibility of cooperation between agents, which allows to use the accumulated experience;

4. Ability to automatically adjust and refine data using context and user models.

In Russia there are multi-agent systems Autonomy and Web Compass, designed for intelligent communication and processing of information on the Internet.

When using mobile agents, a number of serious problems must be solved, including: the legality of ways to move agents over the network; Verification of agents (e.g. protection against problems); Respect for private property rights; maintaining confidentiality of information; overpopulation of network by agents; Compatibility between the agent code and the firmware of the network machine.

The main efforts to improve online mobile search agents on the Internet are aimed at developing models of presentation of knowledge, methods of output of new knowledge, models of reasoning and ways of training agents to ensure full interaction of mobile smart agent ensembles with technological platforms and analytical systems. The improvement of interaction of smart mobile agents is facilitated by the case of a creative ensemble of intelligent interoperable agents [9-20].

\section{Case of Creative Ensemble of Intelligent Interoperable Agents}

Table 1. General.

\begin{tabular}{|c|c|c|c|c|}
\hline Use case name & \multicolumn{4}{|c|}{ Application of creative ensemble of intelligent interoperable agents } \\
\hline Application domain & \multicolumn{4}{|c|}{ Hi-Tech Labor Market } \\
\hline Deployment Model & \multicolumn{4}{|c|}{ Human digital double } \\
\hline Status & \multicolumn{4}{|c|}{ Results of research: Strong Artificial Distributed Intelligence } \\
\hline Objective (s) & \multicolumn{4}{|c|}{ Find accurate and universal application of strong artificial distributed intelligence } \\
\hline & \multicolumn{4}{|c|}{$\begin{array}{ll}\text { Short description } & \text { Creative ensemble is complex of intelligent interoperable agents interacting through smart interface, } \\
\text { (not more than } & \text { implementing either technological process, social services, multi-inter- trans-disciplinary research, or } \\
150 \text { words) } & \text { production cycle. }\end{array}$} \\
\hline & & \multirow{2}{*}{\multicolumn{3}{|c|}{$\begin{array}{l}\text { Creative ensemble is complex of intelligent interoperable agents interacting through smart interface, } \\
\text { implementing either technological process, social services, multi-inter- trans-disciplinary research, or } \\
\text { production cycle. In the creative ensemble, the whole range of tasks by certain rules is distributed among } \\
\text { all agents. Job allocation means assigning each agent a role whose complexity is determined by the agent's } \\
\text { capabilities. To organize the task distribution process, the creative ensemble creates either a distributed } \\
\text { problem solution system or decentralized artificial intelligence. In the first version, the process of } \\
\text { decomposition of the global problem and the inverse process of composition of the found solutions takes } \\
\text { place under the control of some single "center." At the same time, the creative ensemble is designed strictly } \\
\text { from top to bottom, based on the roles defined for the agents and the results of dividing the global task into } \\
\text { subtasks. In the case of decentralized artificial intelligence, task distribution occurs during agent } \\
\text { interaction and is synergistic. }\end{array}$}} \\
\hline Narrative & $\begin{array}{l}\text { Complete } \\
\text { description }\end{array}$ & & & \\
\hline Stakeholders & \multicolumn{4}{|c|}{ Highly technological producer } \\
\hline $\begin{array}{l}\text { Stakeholders' assets, } \\
\text { values }\end{array}$ & \multicolumn{4}{|l|}{ Reputation } \\
\hline $\begin{array}{l}\text { System's threats and } \\
\text { vulnerabilities }\end{array}$ & \multicolumn{4}{|c|}{ Legal and ethical aspects of interaction with society. } \\
\hline \multirow[b]{2}{*}{$\begin{array}{l}\text { Key performance } \\
\text { indicators (KPIs) }\end{array}$} & ID & Name & Description & $\begin{array}{l}\text { Reference to } \\
\text { mentioned use case } \\
\text { objectives }\end{array}$ \\
\hline & 1 & $\begin{array}{l}\text { AI management of } \\
\text { professional } \\
\text { cooperation } \\
\text { process }\end{array}$ & $\begin{array}{l}\text { The technology of creative processes control can itself } \\
\text { predict optimal terms of execution of certain stages on the } \\
\text { basis of accumulated information about their labour } \\
\text { intensity, selection of the route of staff load and } \\
\text { competences of employees. Optimize processes during their } \\
\text { execution - automatic delegation of tasks taking into account }\end{array}$ & Improve accuracy \\
\hline
\end{tabular}




\begin{tabular}{|c|c|c|c|c|}
\hline & 2 & $\begin{array}{l}\text { Productivity and } \\
\text { quality AI }\end{array}$ & $\begin{array}{l}\text { the load of employees and their competences. } \\
\text { Strong artificial intelligence works with fewer mistakes and } \\
\text { is safer. Strong artificial improves the quality of life of man } \\
\text { and society in daily concerns, as well as productivity in } \\
\text { high-tech industry and production. }\end{array}$ & Improve efficiency \\
\hline \multirow{5}{*}{ AI features } & Task (s) & \multicolumn{3}{|l|}{ Creative activity } \\
\hline & Method (s) & \multicolumn{3}{|c|}{ Deep learning } \\
\hline & Hardware & \multicolumn{3}{|c|}{ Supercomputer with Strong Artificial Distributed Intelligence } \\
\hline & Topology & \multicolumn{3}{|c|}{ Distributed Modular Interconnect Topology } \\
\hline & $\begin{array}{l}\text { Terms and } \\
\text { concepts used }\end{array}$ & \multicolumn{3}{|c|}{ Deep learning, "imagification", neural network, training, training data set } \\
\hline \multirow{2}{*}{\multicolumn{5}{|c|}{ Strong artificial distributed intelligence requires process standardization, as does every human activity. }} \\
\hline & & \multicolumn{3}{|c|}{ Qualitatively new type of thinking not available to humans. } \\
\hline Challenges and issues & Description & Security and ethic & ind legal aspects & \\
\hline Societal concerns & $\begin{array}{l}\text { SDGs to be } \\
\text { achieved }\end{array}$ & \multicolumn{3}{|c|}{ Universal approach to big data processing with smart cognitive systems } \\
\hline
\end{tabular}

Table 2. Data.

\begin{tabular}{ll}
\hline Data characteristics & \\
\hline Description & Strong Artificial Distributed Intelligence Data \\
Source & Model and technology of Strong Artificial Distributed Intelligence \\
Type & Strong \\
Volume (size) & Hi-Tech Labor Market \\
Velocity (e.g. real time) & Supercomputering Velocity \\
Variety (multiple datasets) & streams of multiple datasets \\
Variability (rate of change) & Retraining \\
Quality & High \\
\hline
\end{tabular}

Table 3. Process scenario.

\begin{tabular}{|c|c|c|c|c|c|}
\hline \multicolumn{6}{|c|}{ Scenario conditions } \\
\hline N. & Scenario name & Scenario description & Triggering event & Pre-condition & Post-condition \\
\hline 1 & Training & $\begin{array}{l}\text { Train a model (deep neural } \\
\text { network) with training data set }\end{array}$ & $\begin{array}{l}\text { Technological process raw data } \\
\text { set is ready }\end{array}$ & Formatting of data & Management of safety \\
\hline 2 & Evaluation & Expansion of the trained model & $\begin{array}{l}\text { Development of technological } \\
\text { thinking and behaviour }\end{array}$ & $\begin{array}{l}\text { Cognitive thinking patterns } \\
\text { and psychological } \\
\text { behaviors }\end{array}$ & $\begin{array}{l}\text { Meeting KPI } \\
\text { requirements is condition } \\
\text { of development }\end{array}$ \\
\hline 3 & Execution & Model and Technology Tooling & Interaction & Activization of Model & $\begin{array}{l}\text { Completion of } \\
\text { interaction }\end{array}$ \\
\hline 4 & Retraining & $\begin{array}{l}\text { Retrain a model with training } \\
\text { data set }\end{array}$ & $\begin{array}{l}\text { Certain period of time has passed } \\
\text { since the last training/retraining }\end{array}$ & $\begin{array}{l}\text { Additional data and } \\
\text { knowledge }\end{array}$ & $\begin{array}{l}\text { Combining Data and } \\
\text { Knowledge }\end{array}$ \\
\hline
\end{tabular}

Table 4. Training.

\begin{tabular}{|c|c|c|c|c|c|}
\hline Scenario name & Training & & & & \\
\hline Step No. & Event & Name of process/Activity & Primary actor & Description of process/activity & Requirement \\
\hline 1 & $\begin{array}{l}\text { Sample raw } \\
\text { data set is ready }\end{array}$ & $\begin{array}{l}\text { Specification and } \\
\text { classification }\end{array}$ & Manufacturer & Transform sample raw data & $\begin{array}{l}\text { Distributed AI } \\
\text { Software }\end{array}$ \\
\hline 2 & $\begin{array}{l}\text { Completion of } \\
\text { Step } 1\end{array}$ & $\begin{array}{l}\text { Creating Set of } \\
\text { Experimental Data }\end{array}$ & Manufacturer & $\begin{array}{l}\text { Development of set of experimental data } \\
\text { through job modelling }\end{array}$ & $\begin{array}{l}\text { Software of } \\
\text { modelling }\end{array}$ \\
\hline 3 & $\begin{array}{l}\text { Completion of } \\
\text { Step } 2\end{array}$ & Model training & $\begin{array}{l}\text { AI solution } \\
\text { provider }\end{array}$ & $\begin{array}{l}\text { Train a model (deep neural network) with } \\
\text { experimental data set created by Step } 2\end{array}$ & Big SD \\
\hline
\end{tabular}

Table 5. Evaluation.

\begin{tabular}{|c|c|c|c|c|c|}
\hline Scenario name & Evaluation & & & & \\
\hline Step No. & Event & Name of process/Activity & Primary actor & Description of process/activity & Requirement \\
\hline 1 & $\begin{array}{l}\text { Completion of } \\
\text { training/retraining }\end{array}$ & Research & Manufacturer & $\begin{array}{l}\text { Train model (deep neural network) } \\
\text { with experimental data set created }\end{array}$ & Big SD \\
\hline 2 & $\begin{array}{l}\text { Completion of } \\
\text { Step } 1\end{array}$ & Identification & AI solution provider & $\begin{array}{l}\text { Based on data, detect execution } \\
\text { using a deep neural network trained } \\
\text { in learning scenario }\end{array}$ & Big SD \\
\hline 3 & $\begin{array}{l}\text { Completion of } \\
\text { Step } 2\end{array}$ & Evaluation & Manufacturer & $\begin{array}{l}\text { Comparison of phase } 2 \text { results with } \\
\text { human performance }\end{array}$ & $\begin{array}{l}\text { Efficiency and } \\
\text { quality }\end{array}$ \\
\hline \multicolumn{2}{|c|}{ Input of evaluation } & Productivity & & & \\
\hline \multicolumn{2}{|c|}{ Output of evaluation } & Efficiency and quality & & & \\
\hline
\end{tabular}


Table 6. Execution

\begin{tabular}{|c|c|c|c|c|c|}
\hline \multirow{2}{*}{$\begin{array}{l}\text { Scenario name } \\
\text { Step No. } \\
\end{array}$} & \multicolumn{5}{|l|}{ Execution } \\
\hline & Event & Name of process/Activity & Primary actor & Description of process/activity & Requirement \\
\hline 1 & $\begin{array}{l}\text { Completion of comparison } \\
\text { of modeling results with } \\
\text { human performance }\end{array}$ & Research & Manufacturer & $\begin{array}{l}\text { Development of a set of } \\
\text { experimental data through job } \\
\text { modelling }\end{array}$ & Quality \\
\hline 2 & Completion of Step 1 & Identification & Manufacturer & $\begin{array}{l}\text { Based on modified data train } \\
\text { model (deep neural network) with } \\
\text { experimental data set created }\end{array}$ & Compatibility \\
\hline \multicolumn{2}{|c|}{ Input of Execution } & $\begin{array}{l}\text { Modification } \\
\text { Compatibility }\end{array}$ & & & \\
\hline
\end{tabular}

Table 7. Retraining.

\begin{tabular}{|c|c|c|c|c|c|}
\hline Scenario name & Retraining & & & & \\
\hline Step No. & Event & Name of process/Activity & Primary actor & Description of process/activity & Requirement \\
\hline 1 & $\begin{array}{l}\text { Certain period of time } \\
\text { has passed since the last } \\
\text { training/retraining }\end{array}$ & Research & Manufacturer & Additional data and knowledge & Completeness \\
\hline 2 & Completion of Step 1 & $\begin{array}{l}\text { Experimental data set } \\
\text { creation }\end{array}$ & Manufacturer & $\begin{array}{l}\text { Combining Data and Knowledge } \\
\text { Based on modified data train } \\
\text { model (deep neural network) with } \\
\text { experimental data set created }\end{array}$ & Compatibility \\
\hline 3 & Completion of Step 2 & Model training & AI solution provider & $\begin{array}{l}\text { Comparison of phase } 2 \text { results } \\
\text { with human performance }\end{array}$ & $\begin{array}{l}\text { Efficiency } \\
\text { and quality }\end{array}$ \\
\hline \multicolumn{2}{|c|}{ Specification of retraining data } & \multicolumn{4}{|c|}{ Retraining data set has to include recent data } \\
\hline
\end{tabular}

\section{Approach to Secure Use of Intelligent Agents}

Modern artificial intelligence techniques (neural networks, machine learning) and science cannot explain how a trained system makes a decision. Because of this, the price of error in the fields: medicine, defense, judicial practice, etc. In order to apply everywhere, it is necessary to introduce standardization of the use of intelligent agents.

Briefly we will consider approach to standardization on use of intellectual agents in ISO/IEC 22989 - Information Technology - Artificial Intelligence - Artificial Intelligence Concepts and Terminology

It is necessary to add the term and definition of an intelligent ensemble to the standard: an intelligent ensemble is a complex of compatible intelligent agents interacting through an intelligent interface, implementing either a technological process, social services, multidisciplinary interdisciplinary research, or a production cycle.

The following types of classification should be added to the section relating the types of classification to the stages of the life cycle of the system with artificial intelligence:

a) diversification,

b) mobility.

The terms and definitions of diversification and mobility should be added to the standard: diversification is expansion of artificial intelligence functions and mastering of a new type of functionality in order to increase efficiency, quality and functional diversity of the intellectual system; mobility is the ability of an ensemble of intelligent agents to rapidly functional retraining and develop its intelligence.

The definitions of diversification and mobility are consistent with the definitions of the standard: life cycle: development of a system, product, service, project or other human-created entity from design to write-off; life cycle model: structural basis of life cycle processes and actions, which also serves as a common reference for linking and understanding.

Images and numbers are taken as simulation data. The environment is perceived through images and scenes. Scenes consist of a number of images. Scenes are static (paintings) and dynamic. Dynamic scenes are characterized by patterns of behavior of objects and objects. Patterns are either described by formulas or represented by a graph (numerically). Safety of behavior depends on spatial, temporal, substantive, visual and audible sensitivity. Behavior security is provided within image similarity boundaries in a safe environment. Simulation shows that the development of behavioural skills (mobility) and professional skills (diversification) increases sensitivity of environmental perception, reduces risks, increases safety.

It is necessary to adjust the definition of artificial intelligence standard: artificial intelligence is the ability of a system to acquire, process, apply, and diversify knowledge based on prior experience of specific tasks related to with processing data attributes and the mobility of an intelligent system.

Attributes of data. Objects, objects, materials, things, processes, phenomena and other aspects of the physical world have different properties and characteristics. Properties are represented by qualitative attributes. Characteristics are represented by meaningful attributes. A qualitative attribute can be visual or audible. A meaningful attribute can be represented by a number, a language sense value, a visual or audible way, a mathematical or behavioral action, or an algorithm. Meaningful qualitative attributes are big smart 
data of artificial intelligence [6].

Big smart data (Big SD) is collection of qualitative and quantitative attributes related in time, space, and subject area.

Smart data attributes (numbers and images) form a world view. Big SD attributes of the areas of economics, industrial industries, technology, and professions help build and train artificial neural multilayer artificial intelligence networks to manage, make decisions, and make recommendations to professionals and executives. Applied research modeling helps accumulate Big SD scientific attributes in real time and simultaneously use them to deeply train multi-layer artificial neural control networks to simulate applied research, make decisions, and make recommendations to researchers. By modeling, the optimal (equilibrium safe) state of artificial neural networks of intelligent agents and the limits of attribute values relative to this state are determined. Numeric limits are defined for numeric attribute values. For visual and sound images, the limits of similarity to the optimal image are revealed.

The development and use of equilibrium safe intelligent systems can be applied as a criterion for developing companies to the field of artificial intelligence.

\section{Conclusion}

The ability of multi-agent ensembles to interact with technology platforms and analytical systems enables the development and application of artificial intelligence in economics, high-tech industry, scientific research, education, and the formation of intelligent virtual communities at a higher level of interaction with humans and society. Synergistic coordination of the interaction of intelligent virtual communities by agents - coordinators and agents interfaces of multi-agent ensembles in virtual space with man and society will help to increase efficiency, productivity, mobility and agility in solving industrial and social problem. A multi-agent innovation support ensemble can increase the efficiency of innovative development by forming problemoriented innovative structures to generalize business proposals of innovation entities. That is, the formation of virtual business platforms of technological platforms of innovative interaction of subjects of problem-oriented activities. The formation of synergistic artificial intelligence will be facilitated by standardization that takes into account creation, ethical safe use and its development.

\section{References}

[1] Evgeniy Bryndin. Cognitive Robots with Imitative Thinking for Digital Libraries, Banks, Universities and Smart Factories. International Journal of Management and Fuzzy Systems. V. 3, N. 5, 2017, pp 57- 66.

[2] Evgeniy Bryndin. Mainstreaming technological development of industrial production based on artificial intelligence. COJ Technical \& Scientific Research, 2 (3). 2019. Pages: 1-5.

[3] Evgeniy Bryndin. Collaboration Robots as Digital Doubles of Person for Communication in Public Life and Space.
American Journal of Mechanical and Industrial Engineering, Volume 4, Issue 2, 2019. Pages: 35-39.

[4] Evgeniy Bryndin. Practical Development of Creative LifeSaving Strong Artificial Intelligence. Communications, Vol. 7, No. 1, 2019. Pages: 31-39.

[5] Evgeniy Bryndin. Collaboration Robots with Artificial Intelligence as Digital Doubles of Person for Communication in Public Life and Space. Budapest International Research in Exact Sciences (BirEx-Journal), Volume 1, No. 4, 2019. Pages: $1-11$.

[6] Evgeniy Bryndin. Collaboration of Intelligent Interoperable Agents via Smart Interface. International Journal on Data Science and Technology, Vol. 5, Issue 2. 2019.

[7] Evgeniy Bryndin. Robots with Artificial Intelligence and Spectroscopic Sight in Hi-Tech Labor Market. International Journal of Systems Science and Applied Mathematic, V. 4, № 3, 2019. Pages: 31-37.

[8] Evgeniy Bryndin. Human Digital Doubles with Technological Cognitive Thinking and Adaptive Behaviour. Software Engineering, Volume 7, Issue 1, 2019. P. 1-9.

[9] Evgeniy Bryndin. Supercomputer BEG with Artificial Intelligence of Optimal Resource Use and Management by Continuous Processing of Large Programs. International Journal of Research in Engineering, Vol. 1, Issue 2, 2019. Pages: 9-14.

[10] Evgeniy G. Bryndin. Modeling of Transformation of Nanostructures by Cognitive Systems on the Basis of Big Smart Data. International Journal of Artificial Intelligence and Mechatronics. Volume 7, Issue 4. 2019. P. 19-22.

[11] Evgeniy Bryndin. University Creative Mobility Inside Yourself and in Interaction with Social Environment. Social Science Learning Education Journal, Volume 4, Issue 10, 2019. Page: $35-38$.

[12] Bessmertny I., Kulagin V. Semantic Network as a Knowledge Base in Training Systems //Proceedings of 11th IACEE World Conference on Continuing Engineering Education. Atlanta, GE, USA, 2008. - P. 95-99.

[13] Evgeniy Bryndin. Social Cognitive Smart Robots: Guide, Seller, Lecturer, Vacuum Cleaner, Nurse, Volunteer, Security Guard, Administrator. Communications. Volume 7, Issue 1. 2019. Pages: 6-12.

[14] Evgeniy Bryndin, Irina Bryndina. Technological Diagnostics of Human Condition According to Spectral Analysis of Biofield. Advances in Bioscience and Bioengineering. Volume 7, Issue 3, 2019. Pages: 64-68.

[15] Evgeniy Bryndin, Irina Bryndina. International Public Health Care on Basis Healthy Lifestyle. Asian Journal of Medical Science Research \& Review, Volume 1, Issue 2. 2019. Pages: 88-96.

[16] Evgeniy Bryndin Formation Smart Data Science for Automated Analytics of Modeling of Scientific Experiments. American Journal of Software Engineering and Applications. Volume 8, Issue 2, 2019. Pages: 36-43.

[17] Evgeniy Bryndin. Digital technologies of the industry 4.0. / Chepter 10, C. 201-222, Book: Computer Science Advances: Research and Applications.. USA: Nova Science Publisher. 2019. 252 pages. 
[18] Evgeniy Bryndin. Development of sensitivity and active behavior of cognitive robot by means artificial intelligence. International Journal of Robotics Research and Development. VOL - 10, ISSUE - 1; 2020. Pages: 1-11.

[19] Evgeniy Bryndin. Increased Sensitivity and Safety of Cognitive
Robot by Development of Professional and Behavioral Skills. Engineering Mathematics Letters. 2020. In press.

[20] Evgeniy Bryndin. Formation of Information Reason with Artificial Intelligence in Virtual Space. Journal of Communications. Volume 15; Issue 3. 2020. Page: In the press. 